\title{
Interim Guidelines for Pregnant Women During a Zika Virus Outbreak - United States, 2016
}

\author{
Emily E. Petersen, $\mathrm{MD}^{1}$; J. Erin Staples, MD, $\mathrm{PhD}^{2}$; Dana Meaney-Delman, MD³; Marc Fischer, MD²; Sascha R. Ellington, MSPH${ }^{1}$; \\ William M. Callaghan, $\mathrm{MD}^{1}$; Denise J. Jamieson, $\mathrm{MD}^{1}$
}

On January 19, 2016, this report was posted as an MMWR Early Release on the MMWR website (http://www.cdc.gov/mmwr).

$\mathrm{CDC}$ has developed interim guidelines for health care providers in the United States caring for pregnant women during a Zika virus outbreak. These guidelines include recommendations for pregnant women considering travel to an area with Zika virus transmission and recommendations for screening, testing, and management of pregnant returning travelers. Updates on areas with ongoing Zika virus transmission are available online (http://wwwnc.cdc.gov/travel/notices/). Health care providers should ask all pregnant women about recent travel. Pregnant women with a history of travel to an area with Zika virus transmission and who report two or more symptoms consistent with Zika virus disease (acute onset of fever, maculopapular rash, arthralgia, or conjunctivitis) during or within 2 weeks of travel, or who have ultrasound findings of fetal microcephaly or intracranial calcifications, should be tested for Zika virus infection in consultation with their state or local health department. Testing is not indicated for women without a travel history to an area with Zika virus transmission. In pregnant women with laboratory evidence of Zika virus infection, serial ultrasound examination should be considered to monitor fetal growth and anatomy and referral to a maternal-fetal medicine or infectious disease specialist with expertise in pregnancy management is recommended. There is no specific antiviral treatment for Zika virus; supportive care is recommended.

Zika virus is a mosquito-borne flavivirus transmitted primarily by Aedes aegypti mosquitoes $(1,2)$. These vectors also transmit dengue and chikungunya virus and are found throughout much of the Americas, including parts of the United States. An estimated $80 \%$ of persons infected with Zika virus are asymptomatic $(2,3)$. Symptomatic disease is generally mild and characterized by acute onset of fever, maculopapular rash, arthralgia, or nonpurulent conjunctivitis. Symptoms usually last from several days to 1 week. Severe disease requiring hospitalization is uncommon, and fatalities are rare. Guillain-Barré syndrome has been reported in patients following suspected Zika virus infection (4-6).

Pregnant women can be infected with Zika virus in any trimester $(4,7,8)$. The incidence of Zika virus infection in pregnant women is not currently known, and data on pregnant women infected with Zika virus are limited. No evidence exists to suggest that pregnant women are more susceptible to Zika virus infection or experience more severe disease during pregnancy.

Maternal-fetal transmission of Zika virus has been documented throughout pregnancy $(4,7,8)$. Although Zika virus RNA has been detected in the pathologic specimens of fetal losses (4), it is not known if Zika virus caused the fetal losses. Zika virus infections have been confirmed in infants with microcephaly (4), and in the current outbreak in Brazil, a marked increase in the number of infants born with microcephaly has been reported (9). However, it is not known how many of the microcephaly cases are associated with Zika virus infection. Studies are under way to investigate the association of Zika virus infection and microcephaly, including the role of other contributory factors (e.g., prior or concurrent infection with other organisms, nutrition, and environment). The full spectrum of outcomes that might be associated with Zika virus infections during pregnancy is unknown and requires further investigation.

\section{Recommendations for Pregnant Women Considering Travel to an Area of Zika Virus Transmission}

Because there is neither a vaccine nor prophylactic medications available to prevent Zika virus infection, CDC recommends that all pregnant women consider postponing travel to areas where Zika virus transmission is ongoing (10). If a pregnant woman travels to an area with Zika virus transmission, she should be advised to strictly follow steps to avoid mosquito bites $(11,12)$. Mosquitoes that spread Zika virus bite both indoors and outdoors, mostly during the daytime; therefore, it is important to ensure protection from mosquitoes throughout the entire day (13). Mosquito prevention strategies include wearing long-sleeved shirts and long pants, using U.S. Environmental Protection Agency (EPA)-registered insect repellents, using permethrin-treated clothing and gear, and staying and sleeping in screened-in or air-conditioned rooms. When used as directed on the product label, insect repellents containing DEET, picaridin, and IR3535 are safe for pregnant women $(14,15)$. Further guidelines for using insect repellents are available online (http://wwwnc.cdc.gov/travel/page/avoidbug-bites) $(11,15)$. 


\section{Recommendations for Pregnant Women with History of Travel to an Area of Zika Virus Transmission}

Health care providers should ask all pregnant women about recent travel. Women who traveled to an area with ongoing Zika virus transmission during pregnancy should be evaluated for Zika virus infection and tested in accordance with CDC Interim Guidance (Figure). Because of the similar geographic distribution and clinical presentation of Zika, dengue, and chikungunya virus infection, patients with symptoms consistent with Zika virus disease should also be evaluated for dengue and chikungunya virus infection, in accordance with existing guidelines $(16,17)$.

Zika virus testing of maternal serum includes reverse transcription-polymerase chain reaction (RT-PCR) testing for symptomatic patients with onset of symptoms within the previous week. Immunoglobulin $M(\operatorname{IgM})$ and neutralizing antibody testing should be performed on specimens collected $\geq 4$ days after onset of symptoms. Cross-reaction with related flaviviruses (e.g., dengue or yellow fever) is common with antibody testing, and thus it might be difficult to distinguish Zika virus infection from other flavivirus infections. Consultation with state or local health departments might be necessary to assist with interpretation of results (18). Testing of asymptomatic pregnant women is not recommended in the absence of fetal microcephaly or intracranial calcifications.

Zika virus RT-PCR testing can be performed on amniotic fluid $(7,9)$. Currently, it is unknown how sensitive or specific this test is for congenital infection. Also, it is unknown if a positive result is predictive of a subsequent fetal abnormality, and if so, what proportion of infants born after infection will have abnormalities. Amniocentesis is associated with an overall $0.1 \%$ risk of pregnancy loss when performed at less than 24 weeks of

FIGURE. Interim guidance: testing algorithm ${ }^{*}, \mathrm{t}$, for a pregnant woman with history of travel to an area" with Zika virus transmission, with or without clinical illness** consistent with Zika virus disease

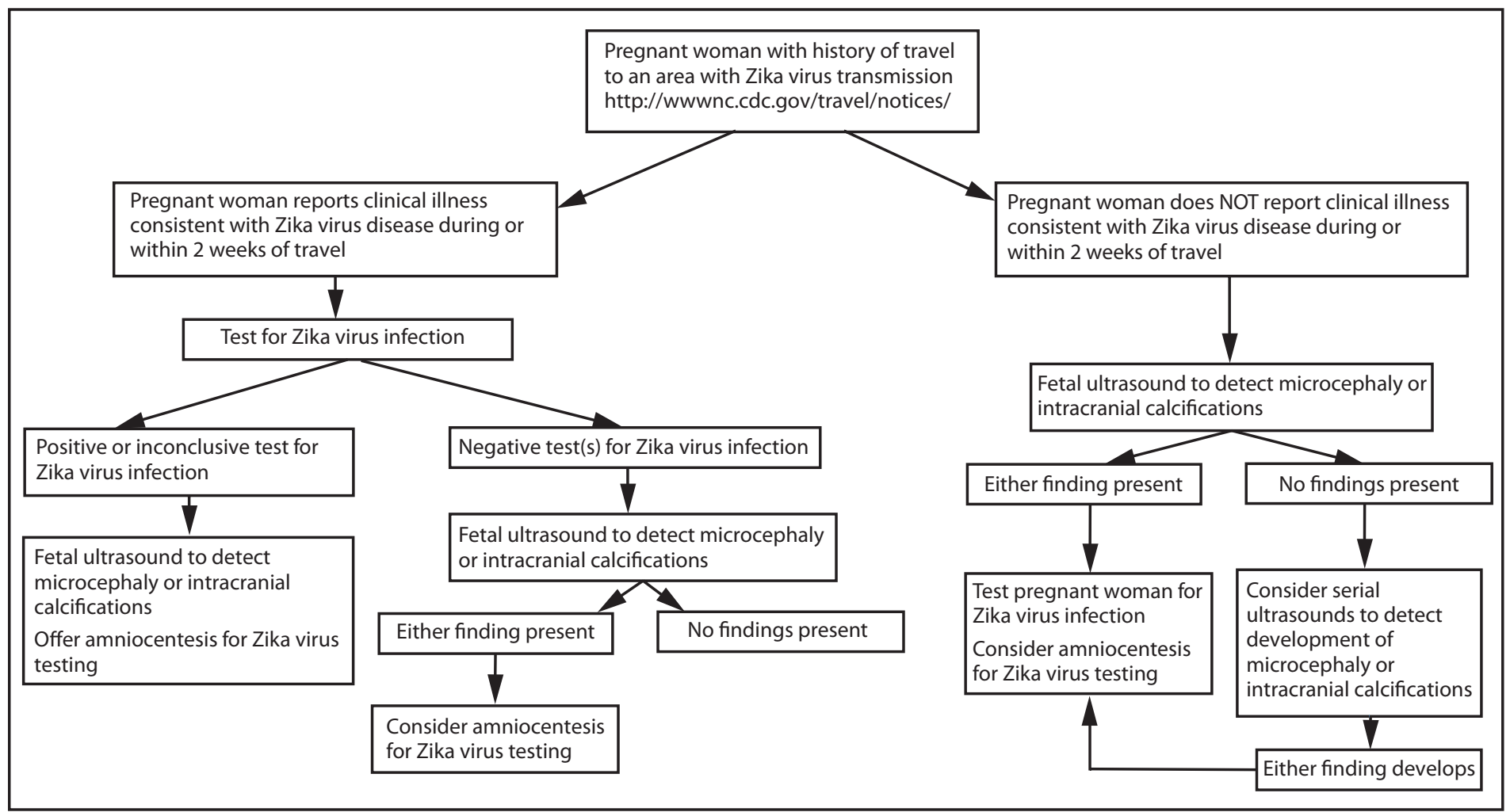

* Availability of Zika virus testing is limited; consult your state or local health department to facilitate testing. Tests include Zika virus reverse transcription-polymerase chain reaction (RT-PCR) and Zika virus immunoglobulin $\mathrm{M}(\mathrm{IgM})$ and neutralizing antibodies on serum specimens. Given the overlap of symptoms and endemic areas with other viral illnesses, evaluate for possible dengue or chikungunya virus infection.

+ Laboratory evidence of maternal Zika virus infection: 1) Zika virus RNA detected by RT-PCR in any clinical specimen; or 2) positive Zika virus IgM with confirmatory neutralizing antibody titers that are $\geq 4$-fold higher than dengue virus neutralizing antibody titers in serum. Testing would be considered inconclusive if Zika virus neutralizing antibody titers are $<4$-fold higher than dengue virus neutralizing antibody titers.

$\S$ Amniocentesis is not recommended until after 15 weeks of gestation. Amniotic fluid should be tested for Zika virus RNA by RT-PCR.

II Updates on areas with ongoing Zika virus transmission are available online (http://wwwnc.cdc.gov/travel/notices/).

* Clinical illness is consistent with Zika virus disease if two or more symptoms (acute onset of fever, maculopapular rash, arthralgia, or conjunctivitis) are present. 
gestation (19). Amniocentesis performed $\geq 15$ weeks of gestation is associated with lower rates of complications than those performed at earlier gestational ages, and early amniocentesis ( $\leq 14$ weeks of gestation) is not recommended (20). Health care providers should discuss the risks and benefits of amniocentesis with their patients. A positive RT-PCR result on amniotic fluid would be suggestive of intrauterine infection and potentially useful to pregnant women and their health care providers (20).

For a live birth with evidence of maternal or fetal Zika virus infection, the following tests are recommended: histopathologic examination of the placenta and umbilical cord; testing of frozen placental tissue and cord tissue for Zika virus RNA; and testing of cord serum for Zika and dengue virus IgM and neutralizing antibodies. CDC is developing guidelines for infants infected by Zika virus. If a pregnancy results in a fetal loss in a woman with history of travel to an area of Zika virus transmission with symptoms consistent with Zika virus disease during or within 2 weeks of travel or findings of fetal microcephaly, Zika virus RT-PCR and immunohistochemical staining should be performed on fetal tissues, including umbilical cord and placenta.

There is no commercially available test for Zika virus. Testing for Zika virus infection is performed at CDC and several state health departments. Health care providers should contact their state or local health department to facilitate testing and for assistance with interpreting results (4).

\section{How to Treat Pregnant Women with Diagnoses of Zika Virus Disease}

No specific antiviral treatment is available for Zika virus disease. Treatment is generally supportive and can include rest, fluids, and use of analgesics and antipyretics (4). Fever should be treated with acetaminophen (21). Although aspirin and other nonsteroidal anti-inflammatory drugs are not typically used in pregnancy, these medications should specifically be avoided until dengue can be ruled out to reduce the risk for hemorrhage $(4,9,17)$.

In pregnant a woman with laboratory evidence of Zika virus in serum or amniotic fluid, serial ultrasounds should be considered to monitor fetal anatomy and growth every 3-4 weeks. Referral to a maternal-fetal medicine or infectious disease specialist with expertise in pregnancy management is recommended.

\footnotetext{
${ }^{1}$ Division of Reproductive Health, National Center for Chronic Disease Prevention and Health Promotion, CDC; ${ }^{2}$ Arboviral Diseases Branch, National Center for Emerging and Zoonotic Infectious Diseases, CDC; ${ }^{3}$ Office of the Director, National Center for Emerging and Zoonotic Infectious Diseases, CDC.

Corresponding author: Denise Jamieson, djj0@cdc.gov, 770-488-6377.
}

\section{References}

1. Hayes EB. Zika virus outside Africa. Emerg Infect Dis 2009;15:1347-50. http://dx.doi.org/10.3201/eid1509.090442.

2. CDC. Zika virus. Atlanta, GA: US Department of Health and Human Services, CDC; 2016. http://www.cdc.gov/zika/index.html.

3. Duffy MR, Chen TH, Hancock WT, et al. Zika virus outbreak on Yap Island, Federated States of Micronesia. N Engl J Med 2009;360:253643. http://dx.doi.org/10.1056/NEJMoa0805715.

4. CDC. CDC health advisory: recognizing, managing, and reporting Zika virus infections in travelers returning from Central America, South America, the Caribbean and Mexico. Atlanta, GA: US Department of Health and Human Services, CDC; 2016. http://emergency.cdc.gov/ han/han00385.asp.

5. Oehler E, Watrin L, Larre P, et al. Zika virus infection complicated by Guillain-Barre syndrome-case report, French Polynesia, December 2013. Euro Surveill 2014;19:4-6. http://dx.doi.org/10.2807/15607917.ES2014.19.9.20720.

6. Musso D, Nilles EJ, Cao-Lormeau VM. Rapid spread of emerging Zika virus in the Pacific area. Clin Microbiol Infect 2014;20:O595-6. http:// dx.doi.org/10.1111/1469-0691.12707.

7. Besnard M, Lastere S, Teissier A, Cao-Lormeau V, Musso D. Evidence of perinatal transmission of Zika virus, French Polynesia, December 2013 and February 2014. Euro Surveill 2014;19:13-6. http://dx.doi. org/10.2807/1560-7917.ES2014.19.13.20751.

8. Oliveira Melo AS, Malinger G, Ximenes R, Szejnfeld PO, Alves Sampaio $S$, Bispo de Filippis AM. Zika virus intrauterine infection causes fetal brain abnormality and microcephaly: tip of the iceberg? Ultrasound Obstet Gynecol 2016;47:6-7. http://dx.doi.org/10.1002/uog.15831.

9. European Centre for Disease Prevention and Control. Rapid risk assessment. Zika virus epidemic in the Americas: potential association with microcephaly and Guillain-Barré syndrome. Stockholm, Sweden: European Centre for Disease Prevention and Control; 2015. http://ecdc. europa.eu/en/publications/Publications/zika-virus-americas-associationwith-microcephaly-rapid-risk-assessment.pdf.

10. CDC. Travelers' health. CDC issues interim travel guidance related to Zika virus for 14 countries and territories in Central and South America and the Caribbean. Atlanta, GA: US Department of Health and Human Services, CDC; 2016. http://wwwnc.cdc.gov/travel/notices.

11. CDC. Travelers' health: avoid bug bites. Atlanta, GA: US Department of Health and Human Services, CDC; 2013. http://wwwnc.cdc.gov/ travel/page/avoid-bug-bites.

12. CDC. Zika virus: prevention. Atlanta, GA: US Department of Health and Human Services, CDC; 2015. http://www.cdc.gov/zika/prevention/ index.html.

13. Schaffner F, Mathis A. Dengue and dengue vectors in the WHO European region: past, present, and scenarios for the future. Lancet Infect Dis 2014;14:1271-80. http://dx.doi.org/10.1016/S1473-3099(14)70834-5.

14. CDC. West Nile virus: insect repellent use \& safety. Atlanta, GA: US Department of Health and Human Services, CDC; 2015. http://www. cdc.gov/westnile/faq/repellent.html.

15. CDC. Travelers' health: protection against mosquitoes, ticks, \&other arthropods. Atlanta, GA: US Department of Health and Human Services, CDC; 2015. http://wwwnc.cdc.gov/travel/yellowbook/2016/the-pre-travel-consultation/ protection-against-mosquitoes-ticks-other-arthropods.

16. CDC. Chikungunya virus: clinical evaluation \& disease. Atlanta, GA: US Department of Health and Human Services, CDC; 2015. http:// www.cdc.gov/chikungunya/hc/clinicalevaluation.html.

17. World Health Organization. Dengue: guidelines for diagnosis, treatment, prevention and control. Geneva, Switzerland: World Health Organization; 2009. http://apps.who.int/iris/bitstream/10665/44188/1/9789241547871_eng.pdf.

18. CDC. Zika virus. For health care providers: diagnostic testing. Atlanta, GA: US Department of Health and Human Services, CDC; 2015. http:// www.cdc.gov/zika/hc-providers/diagnostic.html. 
19. Akolekar R, Beta J, Picciarelli G, Ogilvie C, D’Antonio F. Procedurerelated risk of miscarriage following amniocentesis and chorionic villus sampling: a systematic review and meta-analysis. Ultrasound Obstet Gynecol 2015;45:16-26. http://dx.doi.org/10.1002/uog.14636.

20. American Academy of Pediatrics/American College of Obstetricians and Gynecologists. Guidelines for perinatal care. 7th ed. Elk Grove Village, IL: American Academy of Pediatrics/American College of Obstetricians and Gynecologists; 2012.
21. Rasmussen SA, Kissin DM, Yeung LF, et al.; Pandemic Influenza and Pregnancy Working Group. Preparing for influenza after 2009 H1N1: special considerations for pregnant women and newborns. Am J Obstet Gynecol 2011;204(Suppl 1):S13-20. http://dx.doi.org/10.1016/j. ajog.2011.01.048. 